\begin{tabular}{|c|l|}
\hline Title & Development of an automatic rice quality inspection system \\
\hline Author(s) & Kawamura, Shuso; Natsuga, Motoy asu; Takekura, Kazuhiro; Itoh, Kazuhiko \\
\hline Citation & $\begin{array}{l}\text { Computers and Electronics in Agriculture, 40(1-3), 115-126 } \\
\text { https://doi.org/10.1016/S0168-1699(03)00015-2 }\end{array}$ \\
\hline Issue Date & 2003-10 \\
\hline Doc URL & http://hdl.handle.net/2115/18859 \\
\hline Type & article (author version) \\
\hline File Information & CEA 40-1-3.pdf \\
\hline
\end{tabular}

Instructions for use 


\title{
Development of an Automatic Rice-Quality Inspection System
}

Shuso Kawamura ${ }^{1}$, Motoyasu Natsuga ${ }^{2}$, Kazuhiro Takekura ${ }^{1}$ and Kazuhiko Itoh $^{1}$

\author{
${ }^{1}$ Agricultural Process Engineering Laboratory, Graduate School of Agricultural Science, \\ Hokkaido University, Sapporo 060-8589, Japan. \\ Email,shuso@bpe.agr.hokudai.ac.jp \\ ${ }^{2}$ Section of Agricultural Ecology and Engineering, Faculty of Agriculture, Yamagata \\ University, Tsuruoka 997-8555, Japan
}

\begin{abstract}
The need has arisen in rice-drying facilities in Japan for an automatic method to measure quality aspects of rice when it arrives at the drying facility. A near-infrared (NIR) transmission instrument was used to obtain NIR spectra of damp rough rice and damp brown rice. Calibration models were developed from the original spectra and reference analysis data to determine moisture and protein content of the samples. A visible light (VIS) segregator was used to determine sound whole kernel of brown rice. The precision and accuracy of the NIR instrument and the VIS segregator were found to be sufficiently high to determine moisture and protein content, and sound whole kernel ratio. An automatic rice-quality inspection system was consequently developed. The system consisted of a rice huller, a rice cleaner, an NIR instrument and a VIS segregator, and it was controlled by a computer. Based on the rice-quality information, this system enabled rough rice transported to a rice-drying facility to be classified into six qualitative grades.
\end{abstract}


Keywords: Spectroscopy, Quality, Accuracy, Precision, Validation, Classification

\section{Introduction}

In Japan, harvested rough rice is first transported to rice-drying facilities, where the moisture content of the rough rice is checked at reception. After moisture content inspection, the damp rough rice is dried out to a moisture content level of about $15 \%$ (wet basis), and then the hulls are removed. Brown rice (i.e., rice from which the hulls have been removed) is then transported to rice-mill facilities, where the bran layers and germs are removed. Milled rice is usually used for cooking.

Components of brown rice such as sound whole kernel, immature kernel and underdeveloped kernel, are important for assessing the quality of rice. An inspector belonging to the Japan Food Agency usually visually evaluates the components of the rice as an official inspection when brown rice is shipped after hulling.

The major chemical constituents of milled rice are moisture (15\%), protein (7\%) and starch (77\%). The protein content of milled rice is a very important quality aspect, especially in East Asian countries, where people eat short-grain, non-waxy rice.

Ishima et al. (1974), Yanase et al. (1984), and Shibuya (1990) reported that the protein content of rice is important for the following reasons. Protein inhibits water absorption and starch swelling when milled rice is cooked, and it greatly affects the texture of cooked rice. Rice with high protein content is less sticky when cooked. Since East Asian people prefer sticky cooked rice, rice with low protein content is preferable in East 
Asian countries.

Chikubu et al. (1985) reported that protein content and some other physical properties of rice contribute to about $60 \%$ of the eating quality.

The need has recently arisen in rice-drying facilities in Japan for an automatic method to measure not only moisture content but also other quality aspects of rice in order to grade rough rice according to quality when it arrives at the drying facility.

The objective of this study was to develop an automatic rice-quality inspection system using a near-infrared instrument and a visible light segregator.

2. Materials and methods

\subsection{Rice Samples}

A popular Japanese short-grain, non-waxy variety of rice, “Kirara397”, was used for samples in this study.

2.2 Near-infrared instrument

A near-infrared (NIR) instrument (model Grainspec, Foss Electric, Hillerod, Denmark; Figure 1) was used to obtain NIR spectra of damp whole-grain rough rice and damp whole-grain brown rice. The instrument scanned 33 wavelengths between $825 \mathrm{~nm}$ and $1,075 \mathrm{~nm}$. Damp rough rice and damp brown rice were poured into the hopper of the instrument and loaded automatically into a sample cell. The NIR light that was 
transmitted through the grain sample was detected by a silicon detector, converted into electrical signals, and processed by a computer to be transformed to absorbance (log $(1 / T))$. Several scans for each loading were saved in computer memory. Ten loadings were performed, and the data were averaged to obtain an NIR spectrum for each sample. It took about two minutes to perform ten loadings for one sample. The grain capacity in the sample cell was adjustable according to the type of grain. This capacity was referred to as the light path length of the cell. After a preliminary test, spectral data for damp rough rice were then collected with a light path length of $25 \mathrm{~mm}$, and spectral data for damp brown rice were collected with a light path length of $30 \mathrm{~mm}$.

Moisture content of damp rough rice and damp brown rice samples was determined by the official method of the Japan Food Agency. Five grams of ground rice were placed in a forced air oven at $105^{\circ} \mathrm{C}$ for 5 hours, and moisture content was computed on a wet basis. The damp rough rice grains were dried out to $15 \%$ of moisture content to obtain dried rough rice samples, and the rough rice grains were then hulled to obtain brown rice samples. The brown rice grains were then milled to obtain milled rice samples. Protein content of the brown and milled rice samples was determined by the Kjeldahl method $(\mathrm{N} \times 5.95)$ and calculated on a dry basis. Table 1 shows the precision of the chemical analysis. The standard deviation of differences among repetitions (SDD) in measured moisture content of damp rough rice (0.32\%) and the SDD in measured moisture content of damp brown rice $(0.29 \%)$ were larger than those of dried rice (Natsuga et al., 1992; Kawamura et al., 2002). The SDD data indicated that high-moisture rice had a large moisture distribution. 
Calibration models used to estimate the moisture contents of damp rough rice and damp brown rice were developed from damp rough rice and damp brown rice NIR spectra, respectively. And calibration models used to estimate the protein contents of brown rice and milled rice were also developed from damp rough rice and damp brown rice NIR spectra, respectively. Spectral data analysis software (Data Tracker, Foss Electric, Hillerod, Denmark) was used for chemometric analysis. The samples were randomly divided into two groups: a calibration set containing two thirds of the samples and a validation set containing the remainder (one third) of the samples. The method of partial least squares (PLS) was used to develop calibration models from the original spectra sets. Pretreatment such as smoothing or derivation was not performed on the original spectra.

\subsection{Visible light segregator}

A visible light (VIS) segregator (Model RS-2000X, Shizuoka Seiki, Fukuroi, Japan; Figure 2) was used to determine components of brown rice. Brown rice was poured onto a rotating disk that had oval holes for carrying each rice kernel. Visible light from light-emitting diodes (LED) was used to illuminate rice kernels. A transmission sensor detected interior characteristics (transparency) of each kernel. A reflectance sensor detected appearance characteristics (whiteness) of each kernel. Red, green and blue light detected by another reflectance sensor were used to determine color information from each kernel. An Image sensor detected cracked kernels. Injection nozzles under the rotating disk were used to separate kernels into sound whole kernels, immature kernels, underdeveloped kernels, damaged kernels and discolored kernels through a sample 
manifold. It took about 40 seconds to separate 1000 brown rice kernels into these five types.

As a reference, human visual inspection was performed according to the official inspection standards of the Japan Food Agency. Table 2 shows the precision of the reference human visual analysis. The value of SDD in measured sound whole kernels (0.39\%) was larger than that in discolored kernels (0.06\%). The SDD data indicated that the component with a high percentage had a large distribution.

3. Results and discussion

3.1 Results of constituent contents analysis using NIR instrument

The results of PLS calibration modeling and validation statistics for moisture content and protein content are summarized in Table 3. The coefficients of determination $\left(\mathrm{r}^{2}\right)$ of the validation set were sufficiently high (0.96 and 0.97) for determination of moisture content. The standard errors of prediction (SEP) for moisture content $(0.70 \%$ and $0.50 \%$ ) were slightly worse than those previously reported (Natsuga et al., 1992; Kawamura et al., 2002), because damp rough rice and brown rice had large moisture distributions. However, the results shown in Figure 3 indicate that NIR spectroscopy can be used for accurate determination of the moisture content of damp whole-grain rice.

Brown rice protein content and milled rice protein content were determined using 
calibration models obtained from damp rough rice and damp brown rice spectra, respectively (Table 3). Scatter plots of chemical analysis versus NIR estimated values of the protein content of brown rice are shown in Figure 4, and those of milled rice are shown in Figure 5. The $r^{2}$ values of 0.70 and 0.76 and the SEP values of $0.24 \%$ and $0.22 \%$ were worse than those previously obtained from dried ground milled rice $\left(r^{2}=0.94\right.$ and SEP $=0.17 \%$, Natsuga et al., 1992), dried whole-grain milled rice $\left(r^{2}=0.97\right.$ and $\mathrm{SEP}=0.13 \%$, Delwiche et al., 1996) and dried ground brown rice $\left(\mathrm{r}^{2}=0.98\right.$ and $\mathrm{SEP}=0.15 \%$, Suzuki et al., 1996). In previous studies, the protein contents of brown rice and milled rice were determined from their peculiar spectra, while the protein contents of brown rice and milled rice in this study were determined from damp rough rice spectra.

The results shown in Figures 4 and 5, however, indicate that the NIR instrument had a reasonable capability to classify damp rough rice into high, middle and low protein content groups upon arrival at a drying facility. Shenk and Westerhaus (1993) discussed the relationship between $r^{2}$ and the percentage of times a sample was correctly classified. For example, if damp rough rice samples are divided into three protein content groups by using the calibration model with $\mathrm{r}^{2}$ of 0.76 shown in Figure 5 , about $70 \%$ of the samples could be correctly classified.

\subsection{Results of component analysis using VIS segregator}

The results of validation statistics for component analysis using the VIS segregator are summarized in Table 4. Scatter plots of results of human inspection versus 
segregator-measured values of sound whole kernels are shown in Figure 6, and those of immature kernels are shown in Figure 7. The $r^{2}$ values of 1.00 and 0.99 were sufficiently high, and the SEP values of $0.51 \%$ and $0.91 \%$ were sufficiently low, indicating that the VIS segregator could be substituted for the human visual inspection for component analysis of brown rice.

3.3 Design of an automatic rice-quality inspection system

The precision and accuracy of the NIR instrument and the VIS segregator were sufficiently high to enable accurate classification of rice arrived at a drying facility. Based on the results, an automatic rice-quality inspection system was designed. As shown in Figure 8, the system consisted of a rice huller (an impeller-type huller), a rice cleaner (a thickness grader), an NIR instrument and a VIS segregator. Each rice sample was moved automatically from one apparatus to the next one through tubes by pneumatic conveyors, bucket elevators or by the force of gravity. In this system, rough rice samples should be hulled at first so as not to get stuck in the grain path and also to enable measurement of sound whole kernels of brown rice.

Figure 9 shows a photograph of an inspection room equipped with an NIR instrument, a VIS segregator and a computer. The rice sample passed through a huller and a rice cleaner in a room above the inspection room, and the brown rice dropped down through the ceiling into the inspection room. The computer (local computer) controlled all apparatuses and received information from each apparatus through serial interface (RS-232C) as shown in figure 10. The program for controlling each apparatuses was 
written in Visual C language. The local computer was connected on to local area network in the rice-drying facility. Based on information of quality aspects (protein content, moisture content and sound whole kernel ratio), rough rice transported to the rice-drying facility could be classified into six qualitative grades, i.e. three protein content levels times two sound whole kernel ratios. The host computer of the rice-drying facility (Figure 10) automatically decided which damp holding bin or dryer should be used for the received rough rice according to the quality information.

About two hundred automatic rice-quality inspection systems are currently being used at rice-drying facilities in Hokkaido, the northernmost island of Japan.

\section{Conclusions}

The precision and accuracy of an NIR instrument and a VIS segregator for determining protein content, moisture content and sound whole kernel ratio were sufficiently high to enable classification of rice samples. An automatic rice-quality inspection system consisting of a rice huller, a rice cleaner, an NIR instrument and a VIS segregator was designed. Based on the information of quality aspects, this system enabled rough rice transported to a rice-drying facility to be classified into six qualitative grades.

\section{Acknowledgements}

This research project was supported in part by the Hokkaido Agricultural Structures Council. We are also grateful to Agricultural Cooperatives in Takasu and Uryuu for providing rice samples and to the staffs of Shizuoka Seiki Co., Ltd for their cooperation 
in conducting the experiments.

\section{References}

Chikubu, S., Watanabe, S., Sugimoto, T., Manabe, N., Sakai, F., Taniguchi, Y., 1985. Relation between palatability evaluation of cooked rice and physicochemical properties of rice (part 2) establishment of palatability estimation formula of rice by multiple regression analysis (in Japanese with English abstract). J. of the Japanese Society of Starch Science, 32 (1), 51-60.

Delwiche, S.R., McKenzie, K.S., Webb, B.D., 1996. Quality characteristics in rice by near-infrared reflectance analysis of whole-grain milled samples. Cereal Chemistry, 73 (2), 257-263.

Ishima, T., Taira, Hi., Taira, Ha., Mikoshiba, K., 1974. Effect of nitrogenous fertilizer application and protein content in milled rice on olganoleptic quality of cooked rice (in Japanese with English abstract). Report of National Food Research Institute, Japan, 29, 9-15.

Kawamura, S., Takekura, K., Itoh, K., 2002. Accuracy in determination of rice constituent contents using near-infrared transmission spectroscopy and improvement in the accuracy (in Japanese with English abstract). J. of the Japanese Society of Agricultural Machinery, 64 (1), 120-126. 
Natsuga, M., Kawamura, S., Itoh, K., 1992. Precision and accuracy of near-infrared reflectance spectroscopy in determining constituent content of grain (in Japanese with English abstract). J. of the Japanese Society of Agricultural Machinery, 54 (6), 89-94.

Suzuki, Y., Takahashi, S., Takebe, M., Komae, K., 1996. Factors that affect protein contents in brown rice estimated by a near-infrared instrument (in Japanese with English abstract). Nippon Shokuhin Kogyo Gakkaishi, 43 (2), 203-210.

Shenk, J.S., Westerhaus, M.O., 1993. Analysis of agriculture and food products by near-infrared reflectance spectroscopy. Infrasoft International Co. Port Matilda, PA. USA. PP. 13-16.

Shibuya, N., 1990. Chemical structure of cell walls of rice grain and grain quality (in Japanese with English abstract). Nippon Shokuhin Kogyo Gakkaishi 37 (9), 740-748.

Yanase, H., Ohtsubo, K., Hashimoto, K., Sato, H., Teranishi, T., 1984. Correlation between protein contents of brown rice and textural parameters of cooked rice and cooking quality of rice (in Japanese with English abstract). Report of National Food Research Institute, Japan, 45, 118-122. 
Table 1 Precision of chemical analysis

\begin{tabular}{llccc}
\hline Chemical analysis & Measured sample & $\mathrm{n}^{1}$ & $\begin{array}{c}\text { Range } \\
(\%)\end{array}$ & $\begin{array}{c}\mathrm{SDD}^{2} \\
(\%)\end{array}$ \\
\hline \multirow{2}{*}{ Moisture content } & Damp rough rice & 134 & $15.4-34.8$ & 0.32 \\
\cline { 2 - 5 } & Damp brown rice & 136 & $15.9-32.1$ & 0.29 \\
\hline \multirow{2}{*}{ Protein content } & Brown rice & 150 & $7.3-9.4$ & 0.07 \\
\cline { 2 - 5 } & Milled rice & 150 & $6.7-8.9$ & 0.05 \\
\hline
\end{tabular}

${ }^{1}$ Number of samples.

${ }^{2}$ Standard deviation of differences among repetitions. 
Table 2 Precision of reference human visual analysis

\begin{tabular}{lccc}
\hline Reference analysis & $\mathrm{n}$ & $\begin{array}{c}\text { Range } \\
(\%)\end{array}$ & $\begin{array}{c}\text { SDD } \\
(\%)\end{array}$ \\
\hline Sound whole kernel & 11 & $54.3-97.4$ & 0.39 \\
Immature kernel & 11 & $2.2-24.2$ & 0.34 \\
Underdeveloped kernel & 11 & $0.0-4.7$ & 0.20 \\
Damaged kernel & 11 & $0.3-12.7$ & 0.29 \\
Discolored kernel & 11 & $0.0-2.5$ & 0.06 \\
\hline
\end{tabular}

Abbreviations as in Table 1. 
Table 3 Calibration and validation statistics for moisture content, brown rice protein content and milled rice protein content

\begin{tabular}{|c|c|c|c|c|c|c|c|c|c|c|c|}
\hline \multirow{2}{*}{$\begin{array}{l}\text { Estimated } \\
\text { constituent } \\
\text { content }\end{array}$} & \multirow{2}{*}{$\begin{array}{c}\text { Sample } \\
\text { measured } \\
\text { NIR spectra }\end{array}$} & \multicolumn{5}{|c|}{ Calibration model } & \multicolumn{5}{|c|}{ Validation } \\
\hline & & $\mathrm{n}^{1}$ & $\begin{array}{c}\text { Range } \\
(\%)\end{array}$ & $n F^{2}$ & $r^{23}$ & $\begin{array}{l}\mathrm{SEC}^{4} \\
(\%) \\
\end{array}$ & $\mathrm{n}^{1}$ & $\begin{array}{c}\text { Range } \\
(\%)\end{array}$ & $r^{23}$ & $\begin{array}{l}\mathrm{SEP}^{5} \\
(\%)\end{array}$ & $\begin{array}{r}\text { Bias } \\
(\%) \\
\end{array}$ \\
\hline \multirow{2}{*}{ Moisture content } & Damp rough rice & 90 & $15.4-34.8$ & 7 & 0.97 & 0.70 & 44 & $15.5-33.2$ & 0.96 & 0.70 & -0.04 \\
\hline & Damp brown rice & 96 & $15.9-32.0$ & 8 & 0.99 & 0.37 & 40 & $16.5-32.1$ & 0.97 & 0.50 & 0.06 \\
\hline \multirow{2}{*}{$\begin{array}{l}\text { Brown rice } \\
\text { protein content }\end{array}$} & Damp rough rice & 100 & $7.3-9.4$ & 11 & 0.86 & 0.18 & 48 & $7.4-9.3$ & 0.70 & 0.24 & 0.04 \\
\hline & Damp brown rice & 100 & $7.3-9.4$ & 7 & 0.74 & 0.23 & 48 & $7.4-9.3$ & 0.68 & 0.23 & 0.02 \\
\hline \multirow{2}{*}{$\begin{array}{l}\text { Milled rice } \\
\text { protein content }\end{array}$} & Damp rough rice & 100 & $6.7-8.9$ & 12 & 0.74 & 0.26 & 49 & $6.7-8.7$ & 0.76 & 0.22 & -0.05 \\
\hline & Damp brown rice & 99 & $6.7-8.9$ & 7 & 0.74 & 0.24 & 49 & $6.7-8.7$ & 0.71 & 0.25 & 0.02 \\
\hline
\end{tabular}

${ }^{1}$ Number of samples.

${ }^{2}$ Number of factors.

${ }^{3}$ Coefficient of determination.

${ }^{4}$ Standard error of calibration. $\quad \quad{ }^{5}$ Standard error of prediction. 
Table 4 Validation statistics for component analysis

\begin{tabular}{lcccr}
\hline Component & $\mathrm{n}$ & $\mathrm{r}^{2}$ & $\begin{array}{r}\text { SEP } \\
(\%)\end{array}$ & $\begin{array}{r}\text { Bias } \\
(\%)\end{array}$ \\
\hline Sound whole kernel & 11 & 1.00 & 0.51 & 1.89 \\
Immature kernel & 11 & 0.99 & 0.91 & 0.22 \\
Underdeveloped kernel & 11 & 0.95 & 0.99 & -1.66 \\
Damaged kernel & 11 & 0.99 & 0.83 & 1.48 \\
Discolored kernel & 11 & 0.86 & 0.93 & -1.25 \\
\hline
\end{tabular}

Abbreviations as in Table 3. 


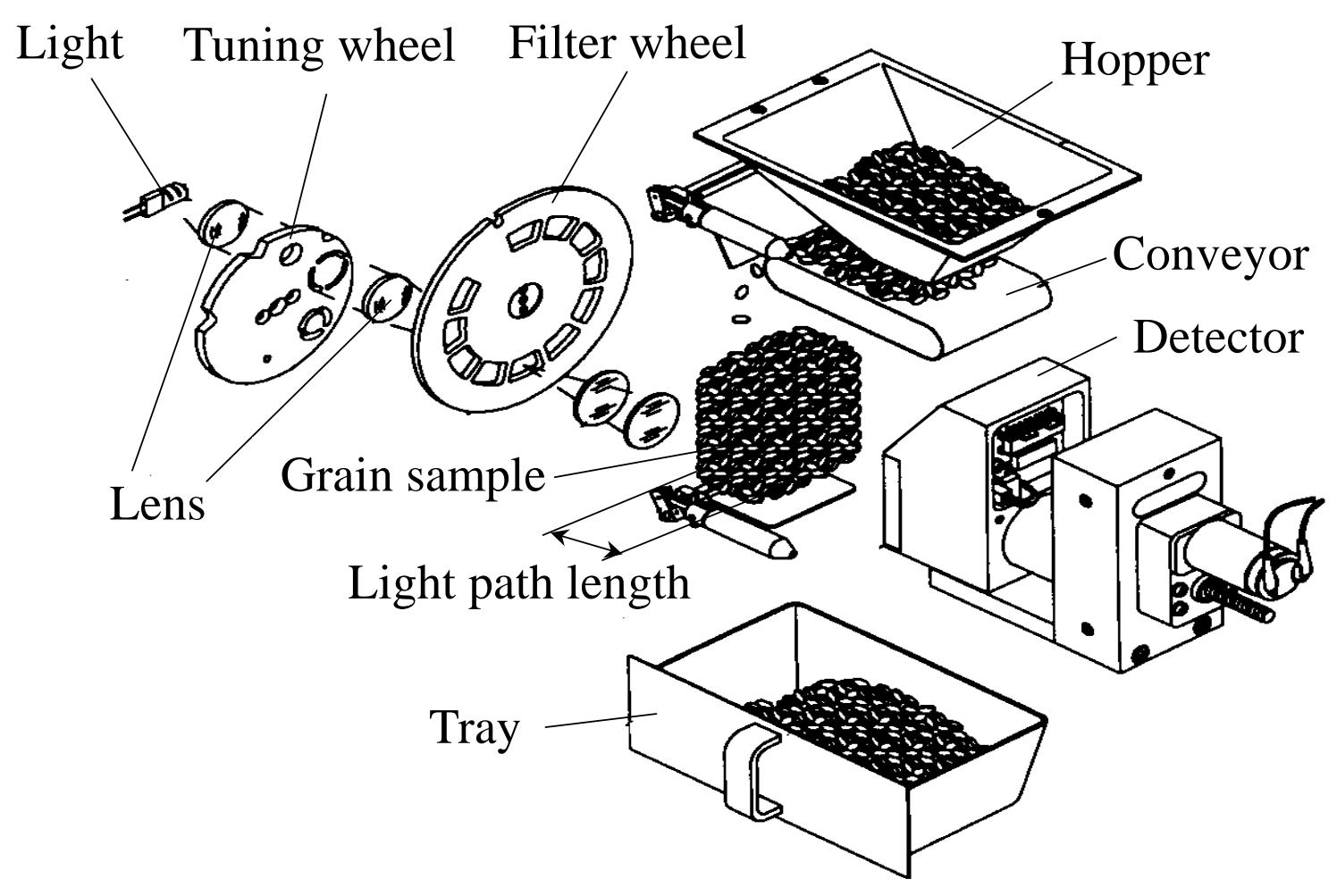

Fig. 1. Near-infrared (NIR) instrument. 


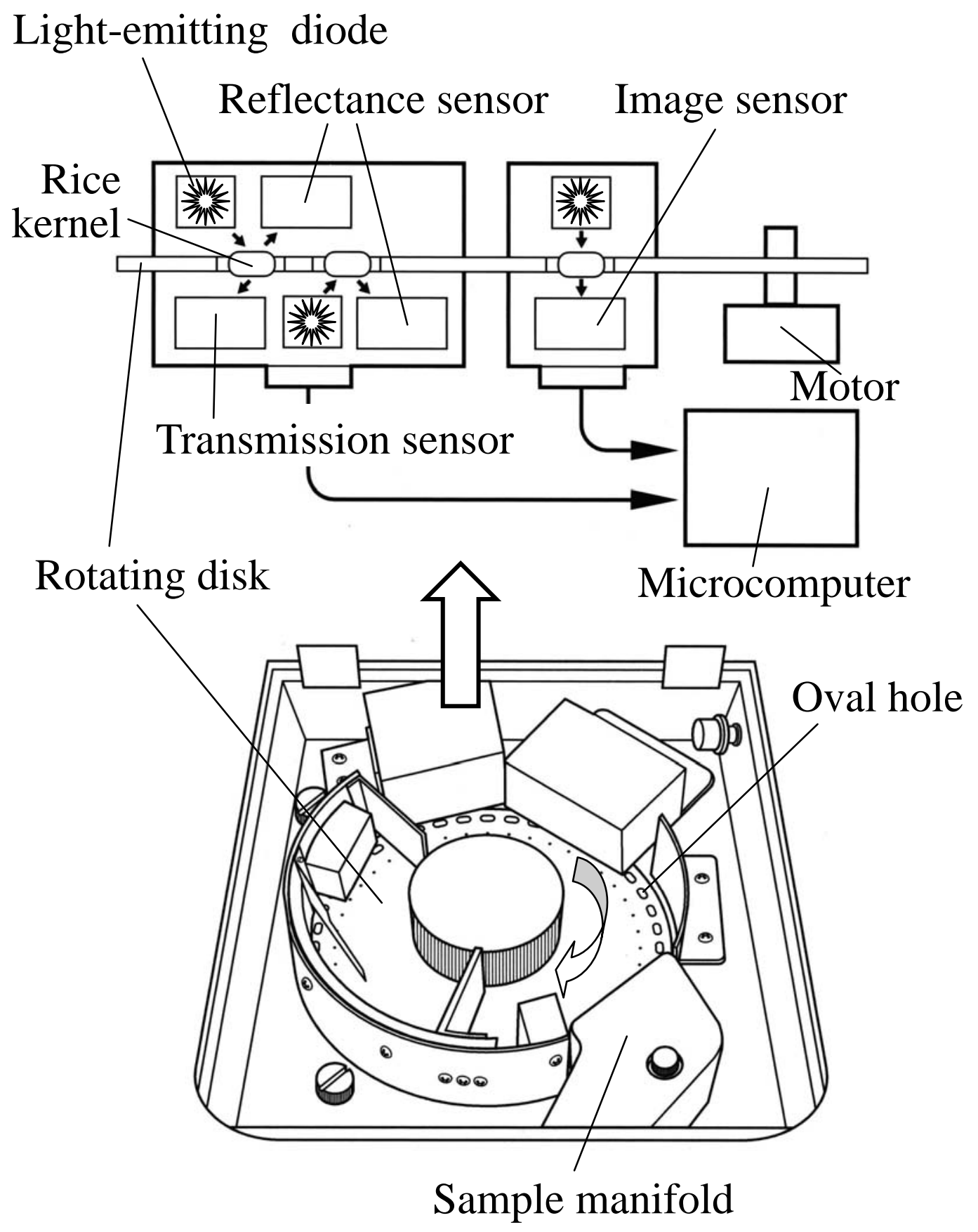

Fig. 2. Visible light (VIS) segregator. 


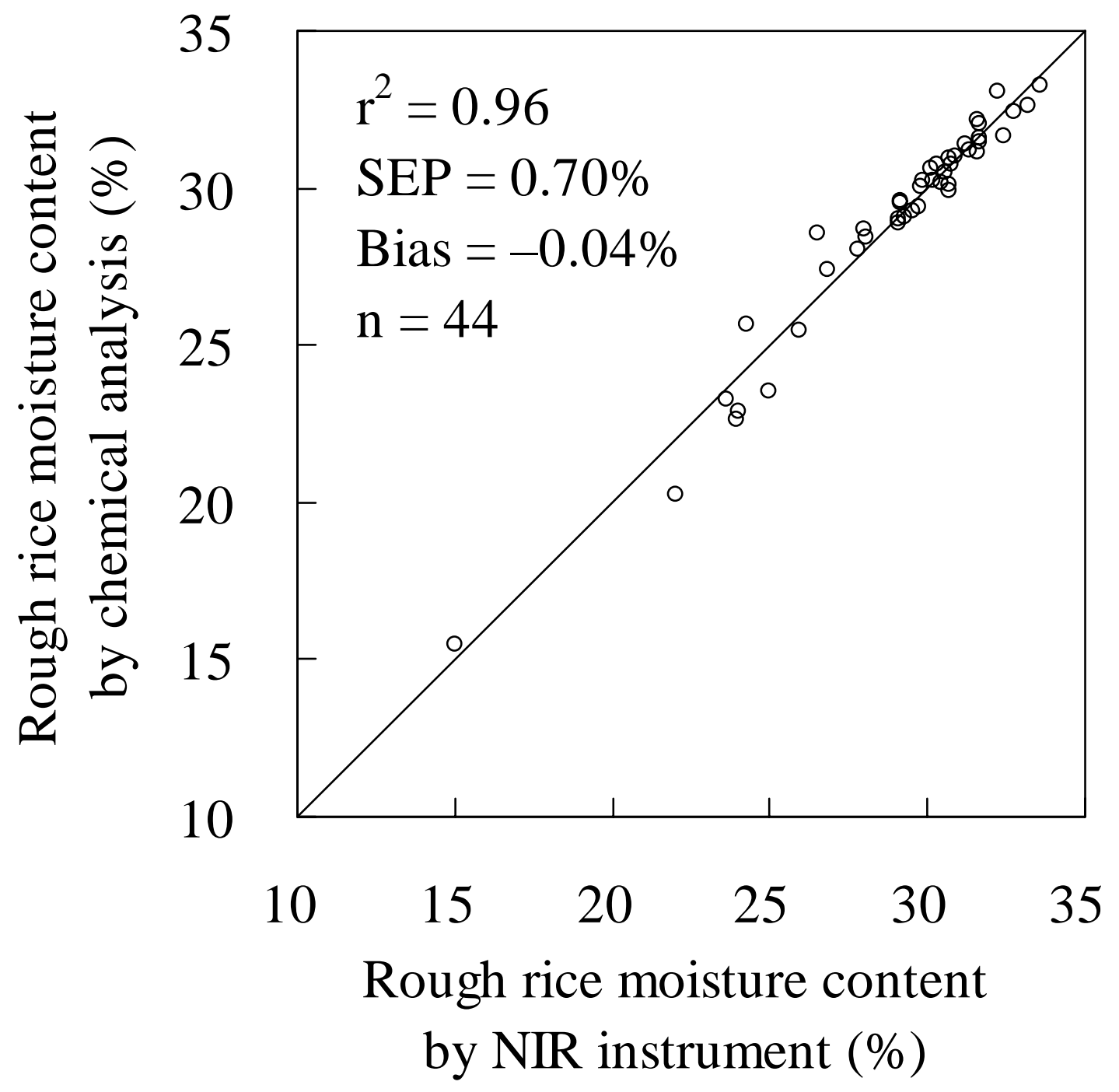

Fig. 3. Validation of the NIR instrument for determining moisture content of damp rough rice. 


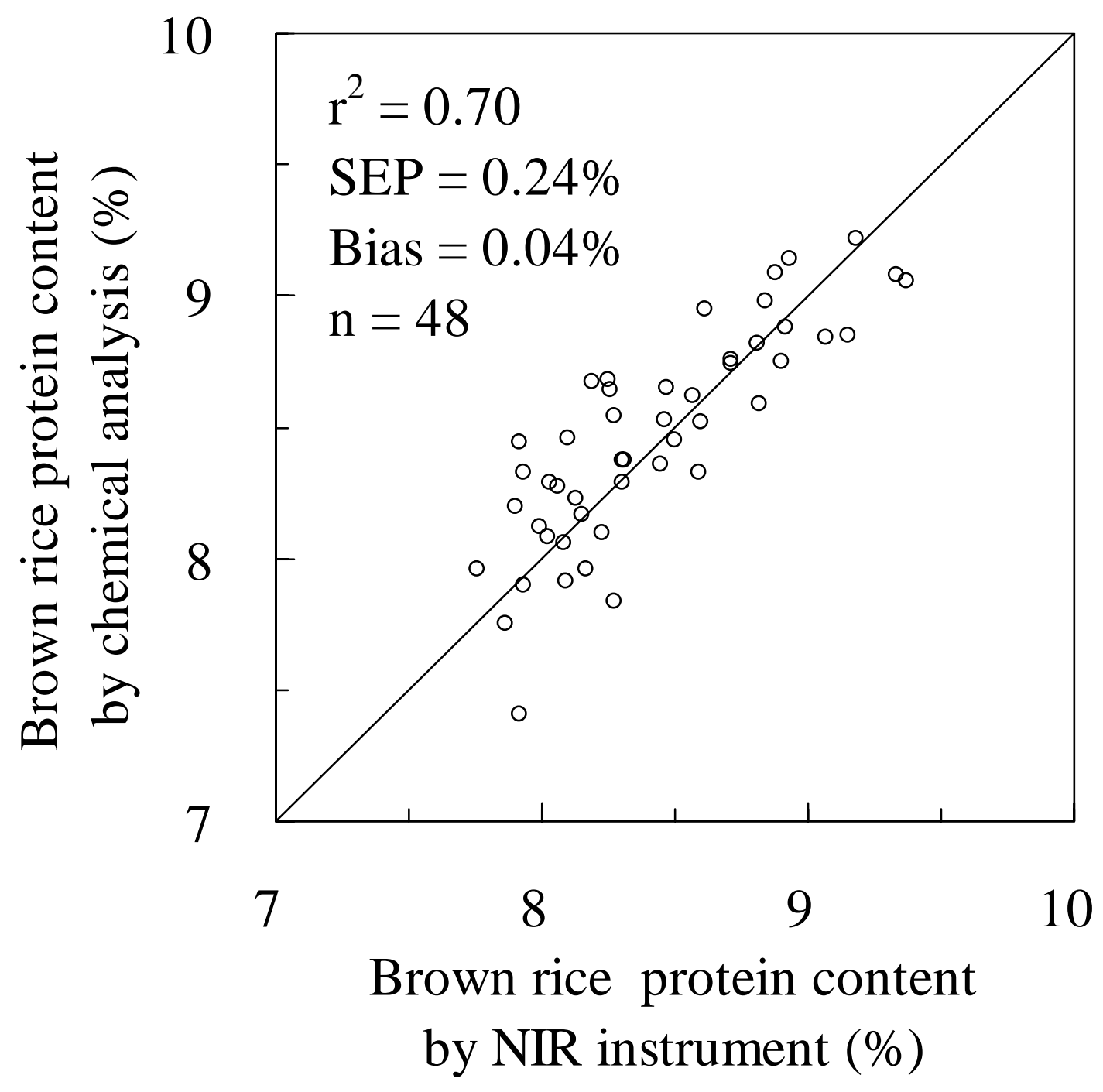

Fig. 4. Validation of the NIR instrument for determining protein content of brown rice using a calibration model obtained from damp rough rice spectra. 


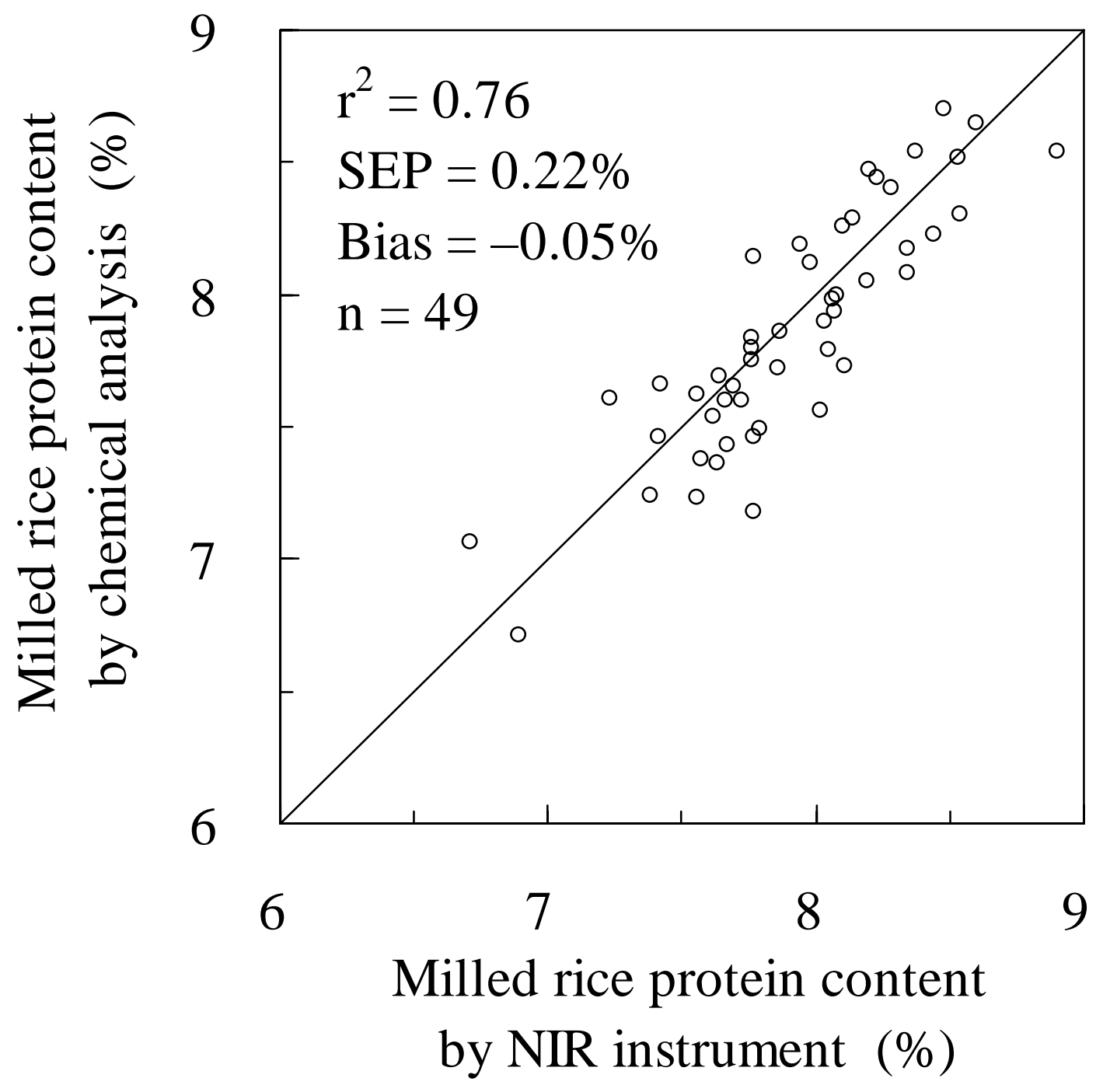

Fig. 5. Validation of the NIR instrument for determining protein content of milled rice using a calibration model obtained from damp rough rice spectra.

Shuso kawamura 


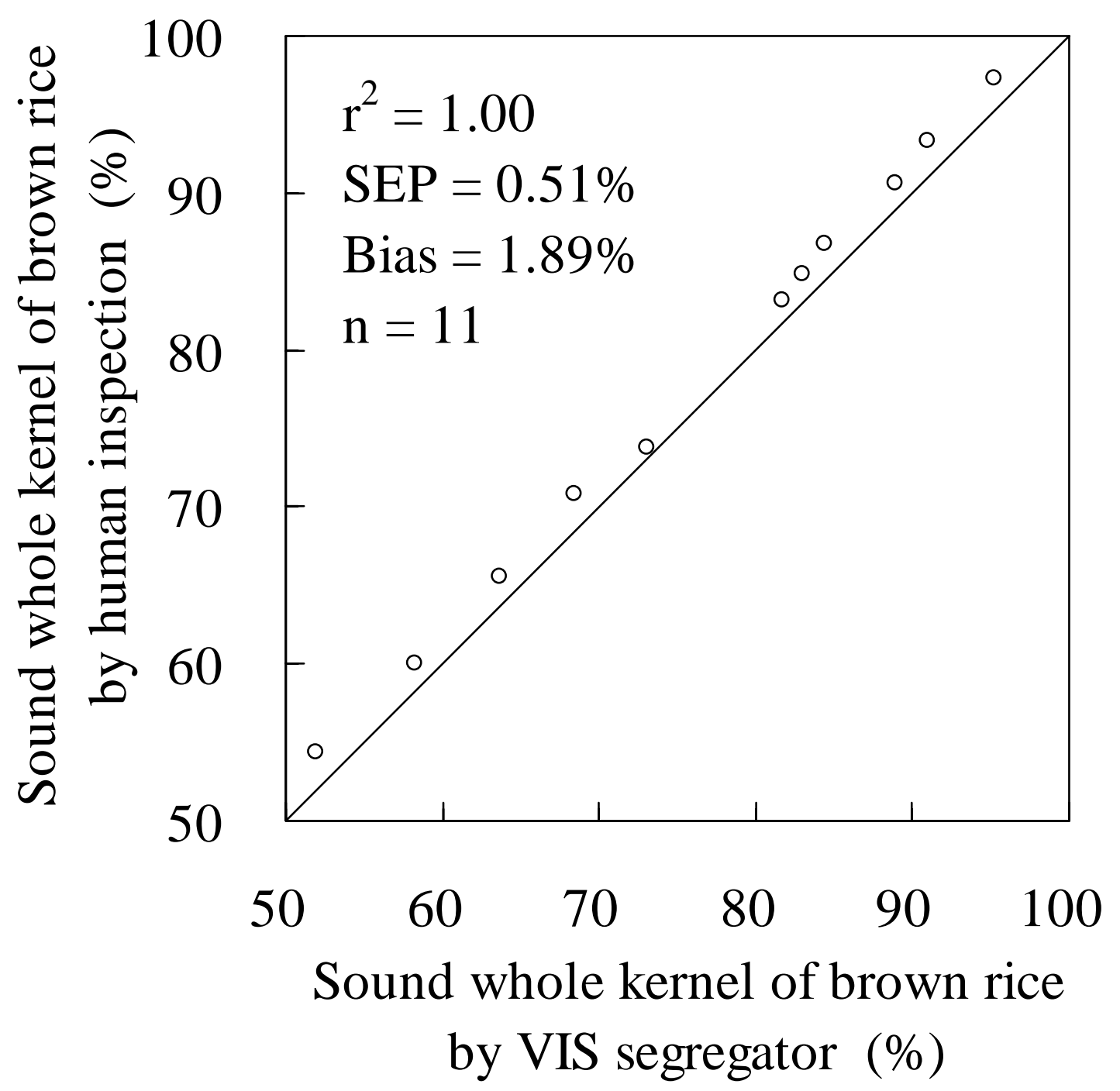

Fig. 6. Validation of the VIS segregator for determining sound whole kernel of brown rice. 


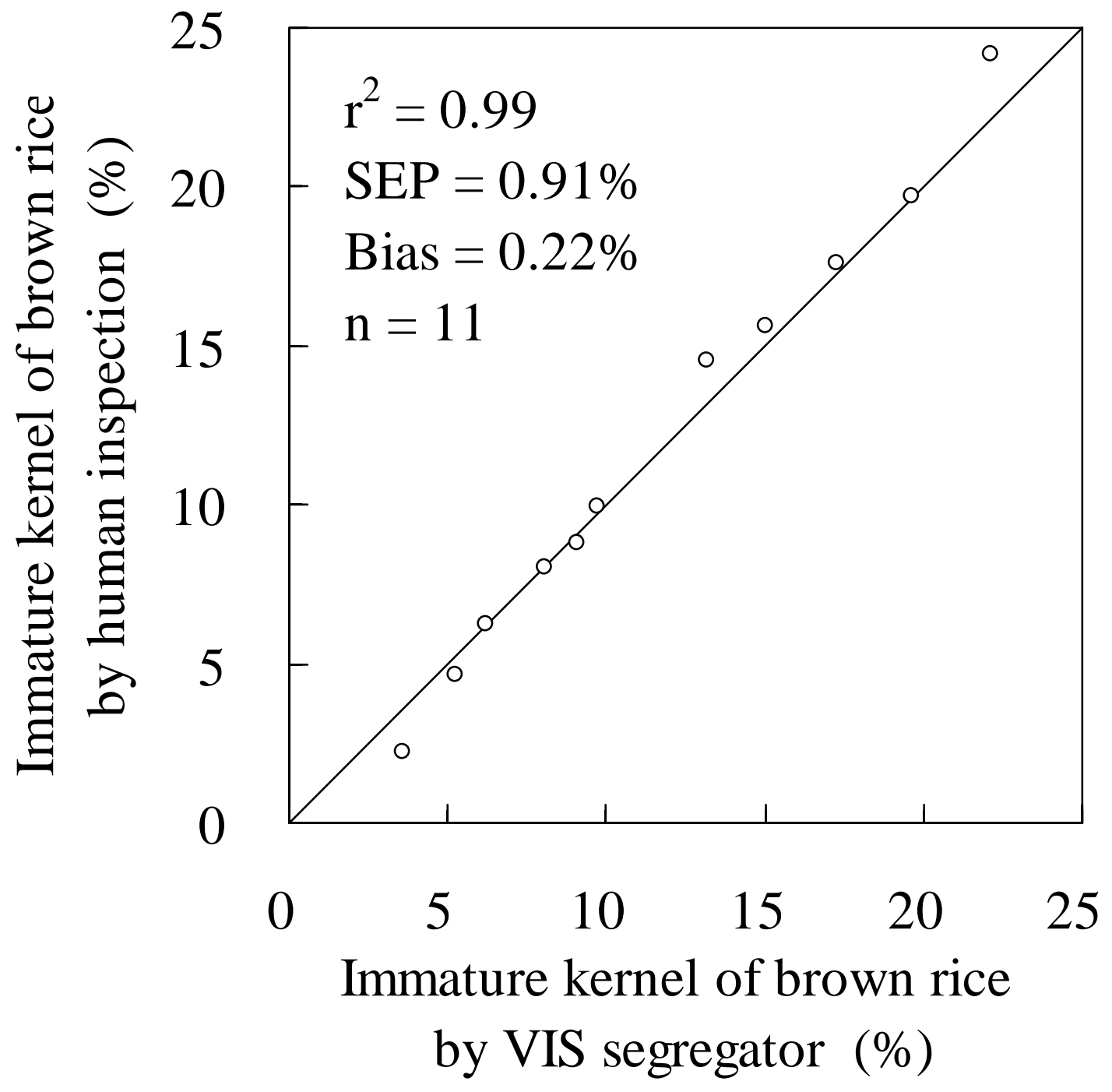

Fig. 7. Validation of the VIS segregator for determining immature kernel of brown rice. 


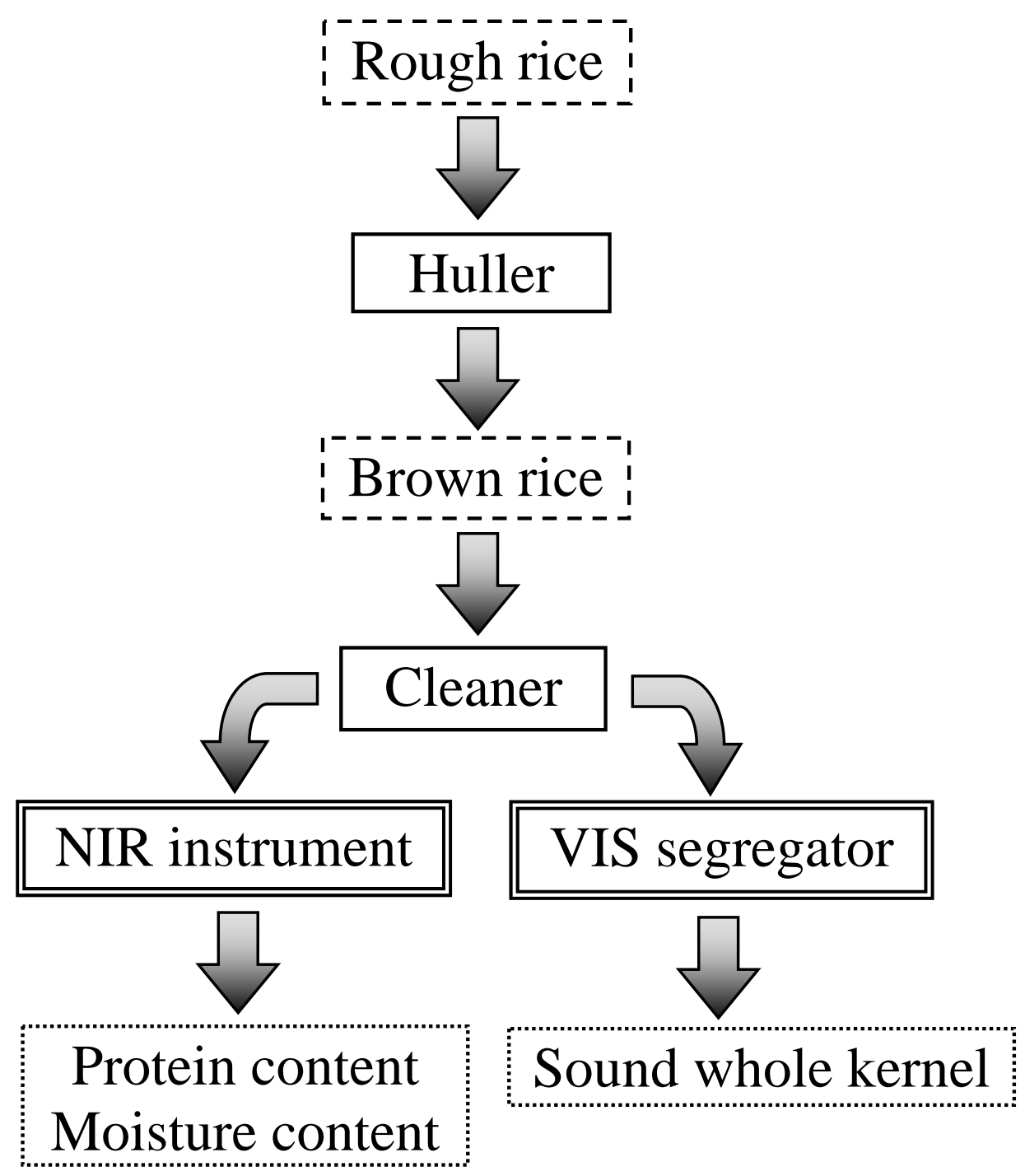

Fig. 8. Flow chart of automatic rice-quality inspection system. 


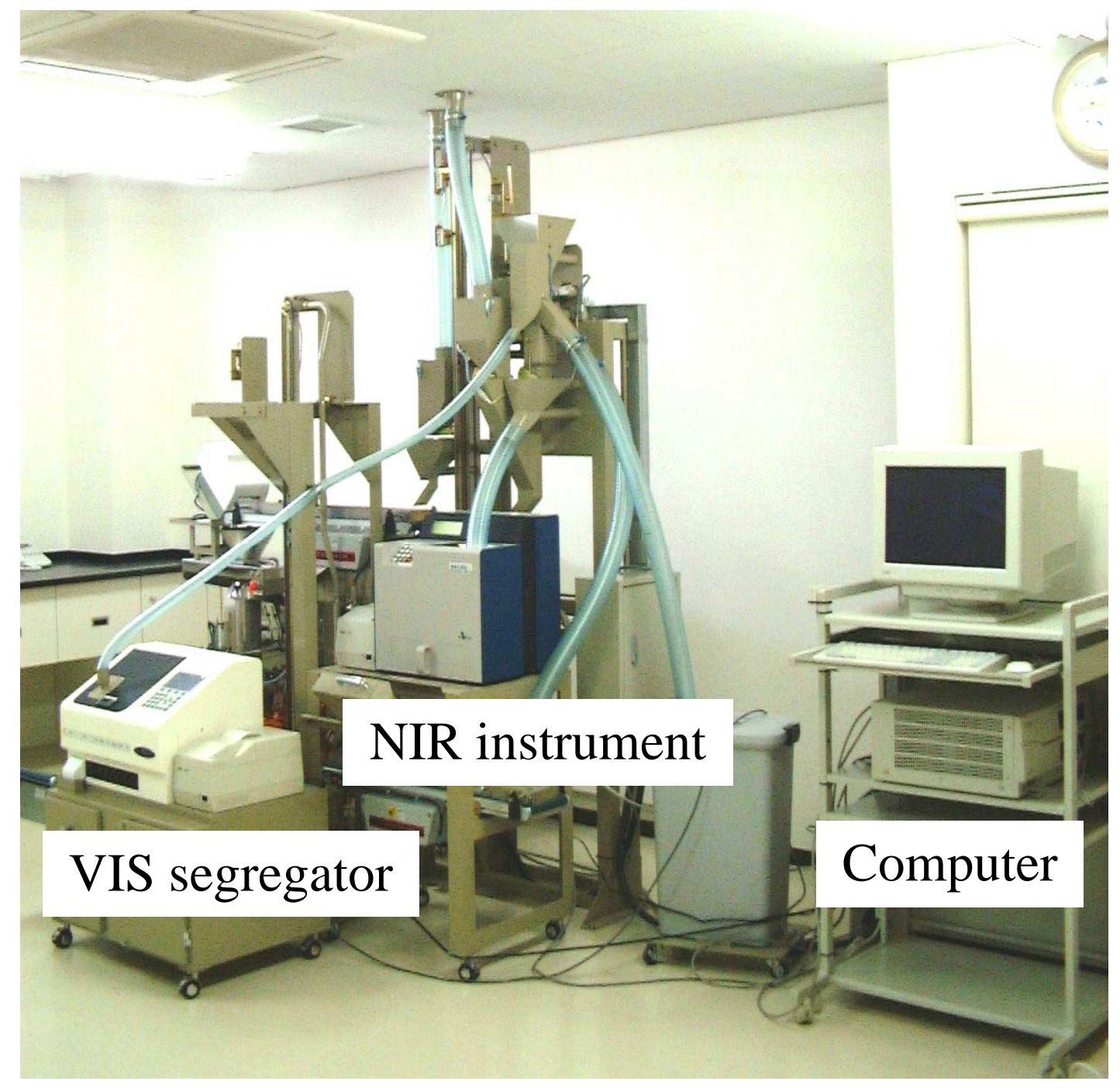

Fig. 9. Inspection room equipped with an NIR instrument, a VIS segregator and a computer. Shuso Kawamura

This photograph is to be printed in monochrome. 


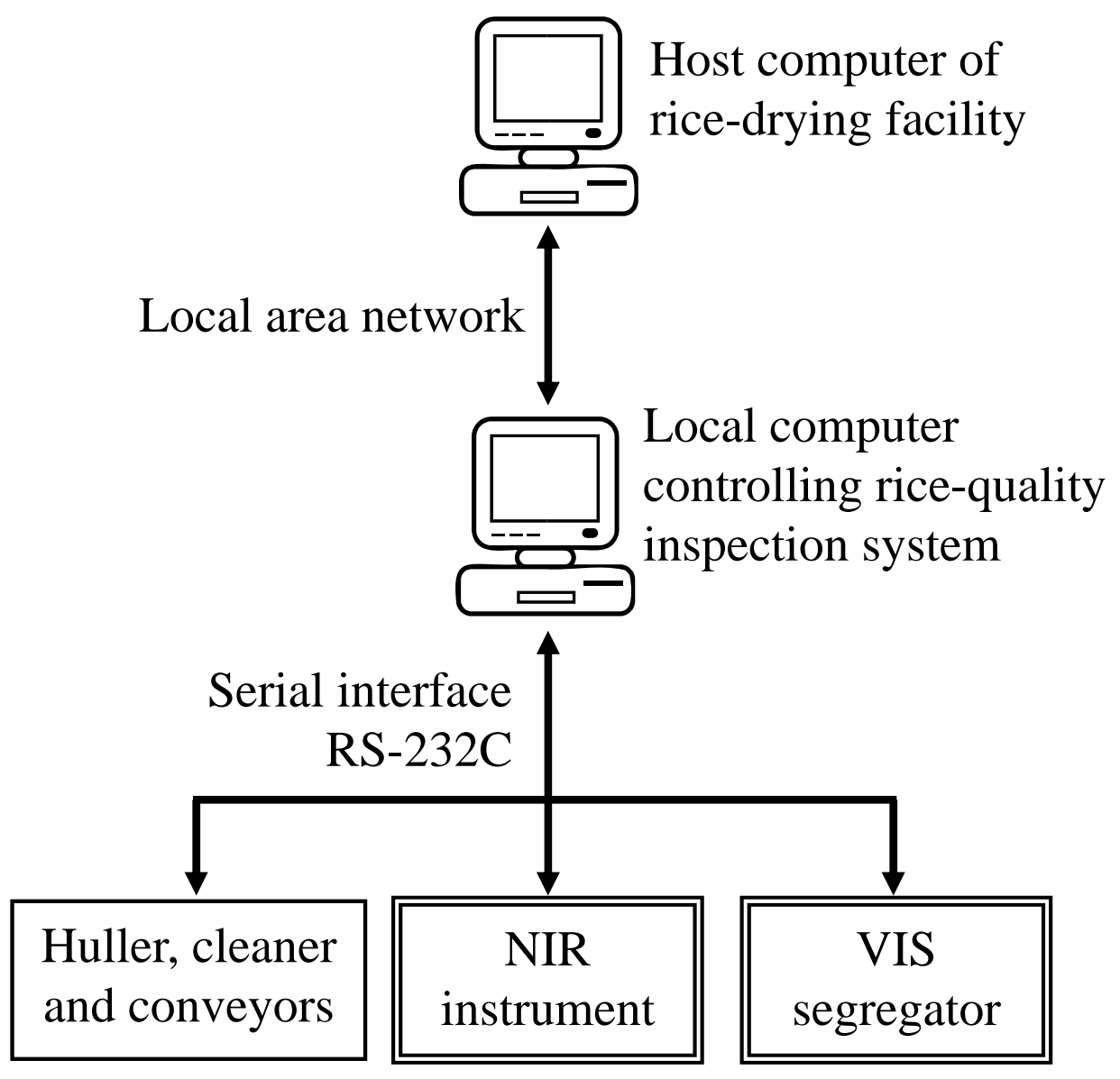

Fig. 10. Computers and control systems for automatic rice-quality inspection system.

Shuso kawamura 